\title{
Refuge
}

Canada's Journal on Refugees

Revue canadienne sur les réfugiés

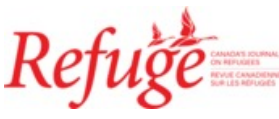

\section{A Reflexive View of Refugee Integration and Inclusion: A Case Study of the Mennonite Central Committee and the Private Sponsorship of Refugees Program}

\section{Luann Good Gingrich and Thea Enns}

Volume 35, Number 2, 2019

Private Sponsorship in Canada

URI: https://id.erudit.org/iderudit/1064816ar

DOI: https://doi.org/10.7202/1064816ar

See table of contents

Publisher(s)

Centre for Refugee Studies, York University

ISSN

0229-5113 (print)

1920-7336 (digital)

Explore this journal

Cite this article

Good Gingrich, L. \& Enns, T. (2019). A Reflexive View of Refugee Integration and Inclusion: A Case Study of the Mennonite Central Committee and the Private Sponsorship of Refugees Program. Refuge, 35(2), 9-23.

https://doi.org/10.7202/1064816ar
Article abstract

Through a qualitative case study with Mennonite Central Committee (MCC) sponsorship groups and former refugee newcomers, we adopt a reflexive, relational, and systemic lens (Bourdieu) to analyze the institutional and interpersonal relationships in the Private Sponsorship of Refugees (PSR) Program, and more specifically, the ways in which MCC Ontario's sponsorship program invigorates or frustrates dynamics of social inclusion. We situate the institutional relations of the PSR Program as nested social fields and sub-fields, revealing complementary and competing systems of capital that direct explicit and implicit visions for "success" in MCC sponsorships. A peculiar Mennonite/MCC social field and structure of capital generates institutional and social tensions, yet an ambivalent disposition or divided habitus presents possibilities for seeing, understanding, and challenging dynamics of social exclusion.
Copyright (c) Refuge: Canada's Journal on Refugees, 2019

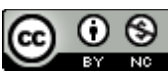

This document is protected by copyright law. Use of the services of Érudit (including reproduction) is subject to its terms and conditions, which can be viewed online.

https://apropos.erudit.org/en/users/policy-on-use/ 


\title{
A Reflexive View of Refugee Integration and Inclusion: A Case Study of the Mennonite Central Committee and the Private Sponsorship of Refugees Program
}

\author{
LUANN GOOD GINGRICH and THEA ENNS ${ }^{1}$
}

\section{Abstract}

Through a qualitative case study with Mennonite Central Committee (MCC) sponsorship groups and former refugee newcomers, we adopt a reflexive, relational, and systemic lens (Bourdieu) to analyze the institutional and interpersonal relationships in the Private Sponsorship of Refugees (PSR) Program, and more specifically, the ways in which MCC Ontario's sponsorship program invigorates or frustrates dynamics of social inclusion. We situate the institutional relations of the PSR Program as nested social fields and subfields, revealing complementary and competing systems of capital that direct explicit and implicit visions for "success" in MCC sponsorships. A peculiar Mennonite/MCC social field and structure of capital generates institutional and social tensions, yet an ambivalent disposition or divided habitus presents possibilities for seeing, understanding, and challenging dynamics of social exclusion.

\section{Résumé}

À travers une étude de cas qualitative avec des groupes de parrainage du Comité Central Mennonite (MCC) et d'anciens nouveaux arrivants comme réfugiés, nous adoptons une perspective réflexive, relationnelle et systémique (Bourdieu) pour analyser les relations institutionnelles et interpersonnelles dans le Programme de parrainage privé des réfugiés, et plus spécifiquement les façons dont le programme de parrainage du MCC Ontario fortifie ou entrave les dynamiques d'inclusion sociale. Nous situons les diverses relations institutionnelles du Programme de parrainage privé des réfugiés comme étant des champs et sous-champs sociaux imbriqués, révélant des systèmes complémentaires et concurrents de capital qui orientent des visions explicites et implicites de la "réussite" dans les parrainages du MCC. Un champ social et une structure de capital Mennonite singuliers génèrent des tensions institutionnelles et sociales.
() Luann Good Gingrich and Thea Enns, 2019. This open-access work is licensed under a Creative Commons Attribution-NonCommercial 4.0 International Licence, which permits use, reproduction, and distribution in any medium for non-commercial purposes, provided the original authorship is credited and the original publication in Refuge: Canada's Journal on Refugees is cited.
Cette œuvre en libre accès fait l'objet d'une licence Creative Commons Attribution-NonCommercial 4.o International License, laquelle autorise l'utilisation, la reproduction et la distribution de l'œuvre sur tout support à des fins non commerciales, pourvu que l'auteur ou les auteurs originaux soient mentionnés et que la publication originale dans Refuge: revue canadienne sur les réfugiés soit citée. 
Toutefois une disposition ambivalente ou un habitus divisé présentent des possibilités pour voir, comprendre et remettre en question les dynamiques d'exclusion sociale.

\section{What Is the Sponsor's Role?}

Your role ... is not to provide instant answers, but rather to encourage the newcomers to weigh and test a variety of possibilities.... Sponsors should be involved in a mutual learning process.... Each culture, and individuals within that culture, have their own way of doing things.... Remember that they, as yourself, need to be treated as people with feelings and needs.... Patience, mutual respect, good humour and love are invaluable assets as you work together in resettlement. $^{2}$

$\mathrm{T}$ he Private Sponsorship of Refugees (PSR) Program in Canada has been hailed by some as an exemplar for social inclusion and integration of refugee newcomers into the host society. This self-proclaimed "pioneering refugee resettlement program,"3 overseen by Immigration, Refugees and Citizenship Canada (IRCC) through the Refugee Sponsorship Training Program (RSTP), gives "ordinary people across the country" the opportunity to use their own personal resources (monetary and otherwise) "to be directly involved in the resettlement of refugees from abroad." 4

According to IRCC, the role of a sponsor, post-arrival, is "to support the refugees for the length of the sponsorship [one year]. This includes help for housing, clothing and food, as well as social and emotional support."5 Sponsoring groups are directed to partner with IRCC-funded Service Provider Organizations (SPOS) to "support the settlement and integration of PSRs."

While settlement and integration are not defined in government documents, emphasis is given to independence and self-sufficiency. For example, the RSTP Handbook for Sponsoring Groups states, "During the first year, newcomers learn a tremendous amount and generally move from a high degree of dependence to a high degree of independence. Through it all, your role is that of an enabler, supporting newcomers to equip themselves, make their own decisions and find out as much as possible about their new environment. Above all, you are providing warm friendship and support." 7

The specific outcomes identified by the Canadian government- "finding employment, learning English, learning life skills to function in Canada" - suggest that priority is placed on effecting individual level adaptation so that the refugee newcomer family reaches economic self-sufficiency through paid work. In contrast, we open this article with an excerpt from a 1979 Mennonite Central Committee (MCC) document when the PSR Program was in its infancy. This passage provides a glimpse of a peculiar Mennonite/MCC ethos that is defined by a non-conformist and communal heritage, culture, and institutional structure. ${ }^{9}$ This, we argue, is consequential for the nature of sponsor-newcomer relationships, associated values and goals, and positions and dispositions that develop through MCC's refugee sponsorships.

We adopt a reflexive, relational, and systemic lens to analyze the institutional and interpersonal relationships in the private sponsorship of refugees. We are most interested in examining the tensions and contradictions of sponsor-newcomer relationships and associated positions and dispositions (or habitus) that are produced, at the institutional and interpersonal scales. We situate the PSR Program as a social field with a particular system of capital and habitus. This theoretical lens brings to our attention the symbolic economy, or logic, of the social relations of private sponsorship, revealing both complementary and competing systems of capital that direct explicit and implicit visions for "success" in MCC sponsorships, and result in institutional and social tensions and an ambivalent disposition or divided habitus. We argue that the "double privatization" of the PSR Program is consequential, even in shaping individual private sponsorship roles and associated dispositions. Equally important in this case example is the unique synergies between MCC as an organization and the congregations that make up its base of support, many of which have sponsored refugees for a sustained period of time. Thus, we theorize, these local and global synergies reproduce a distinct Mennonite ethos (or social field) that is embodied in institutions and individuals.

In this article we draw on focus group and interview data with MCC constituent group (CG) members and former refugee newcomers, along with organizational documents, to examine the nature and evolution of the relationships, responsibilities, positions, and dispositions of private sponsorship. ${ }^{10}$ We begin with a brief history of the private refugee sponsorship program in Canada and MCC's part in its development, followed by an outline of this study's theoretical framework and methodology. The bulk of the article is devoted to our analysis of institutional and interpersonal relationships, tensions, contradictions, and possibilities as they emerged in our data.

\section{Private Refugee Sponsorship in Canada}

Complementing Canada's Government-Assisted Refugee (GAR) Program, the 1976 Immigration Act officially institutionalized the PSR Program. Cameron and Labman note that "sponsorship is permitted through three types of sponsorship groups: 'Groups of Five,' 'Community Sponsors', and 'Constituent Groups (CGs),' who are members of an organization that is a Sponsorship Agreement Holder (SAH)."11 As of February 2019, there were 114 SAHs across Canada, ${ }^{12} 75$ per cent of which are connected with religious communities. ${ }^{13}$ Approximately 65 per cent of refugees privately resettled are sponsored or co-sponsored by a SAH. ${ }^{14}$ 
Until recently, much of the literature on private refugee sponsorship has focused on program evaluation and history $^{15}$ and falls within the context of the Indochinese refugee movement, when the program was initially used and internationally recognized. ${ }^{16}$ Research tends to compare refugee resettlement streams (e.g., GARS versus PSRs) or demographic features and is focused more on outcomes for refugee newcomers than on processes and practices in resettlement. ${ }^{17}$ More recently an influx of research has addressed the realities of private sponsorship of Syrian refugee newcomers, considering identity ${ }^{18}$ or motivations and characteristics of sponsors. ${ }^{19}$ There is a much smaller body of literature on the unique history and involvement of MCC during this time and prior to signing the first Master Agreement. ${ }^{20}$ MCC's role in refugee resettlement is acknowledged within the larger fabric of Christian institutions in Canada, ${ }^{21}$ while some literature specifically addresses cross-cultural and religious interactions between Indochinese refugees and their Mennonite sponsors. ${ }^{22}$ Our focus is on the sponsoring relationships within a larger social system and specific social subfield of MCC as a SAH.

\section{Theoretical Considerations: Models of Integration, Social Fields, and Structures of Capital}

Integration and inclusion are regularly considered critical to settlement of refugee newcomers. ${ }^{23}$ In practice, integration and inclusion are often used interchangeably, notwithstanding discrete conceptual roots and distinct vast literatures. Particularly in the context of settlement services for immigrants and refugees, inclusion may emphasize a subjective sense of belonging and trust over the material realities of settlement and integration. ${ }^{24}$

Despite their ubiquity, definitions and indicators of inclusion, or integration, commonly remain implicit and specific to national contexts and cultural trends that shift over time, revealing the normative nature of an unquestioned social ideal. We consider concepts of refugee integration or inclusion to be produced by an assumed logic that is associated with material and symbolic capital (or resources) in a social field.

From an individualistic and categorical point of view, integration is most often equated with participation in various social arenas, and interventions focus on increasing individual capacity for meaningful incorporation into mainstream communities and institutions. For example, the stated objective of settlement services in Canada is "to help them [refugee newcomers] to become participating members of Canadian society as quickly as possible." ${ }^{25}$ This familiar evaluative gaze lands squarely and exclusively on the refugee newcomer, producing an invisible yet idealized individual and collective self. Integration or inclusion through person-change measures-to help them fit into social systems, institutions, and cultural norms-implies a "centre" or series of centres whereby voluntary engagement or mandatory insertion moves an individual from exclusion to inclusion. ${ }^{26}$

Offering more depth of meaning and complexity, a popular analogy for integration or inclusion of immigrants and refugees is a "two-way street," ${ }^{27}$ recognizing the need for reciprocal change between newcomers and hosts, where "both the receiving communities and the newcomers change, and change each other." ${ }^{28}$ Emphasis is placed not only on rights, but also on responsibilities of both the newcomer and residents ${ }^{29}$ to create the "opportunities for the immigrants' full economic, social, cultural and political participation."30 This interpersonal change remains focused on the level of the individual, yet gives some recognition to the self in relation to the Other.

Aiming for a more robust conception of integration, or inclusion, that recognizes refugee newcomers as "stakeholders" in integration rather than sites of intervention, Lamping, Bertolo, and Wahlrab posit that the primary goal of resettlement is not to provide services, but to build relationships and a welcoming community. ${ }^{31}$ Similarly, Hynie's holistic integration model strengthens the emphasis on changes within the social context and on the interrelatedness of different social levels or dimensions. ${ }^{32}$ This shift from the individual to the social as the unit of analysis and site of intervention requires situating the Other in a social context, stressing place change over person change.

A key principle or value that operates in MCC's refugee sponsorship program is a concept of "mutually transformative relationships," 33 suggesting a model of integration or inclusion that expands the sites of intervention to include interpersonal change, place change, and even system change. We propose that an approach to integration or inclusion of refugee newcomers that is congruent with the Mennonite/ MCC ethos (or structure of capital) situates refugee sponsorship within the broader context of forced migration-in conflict that is at once interpersonal and systemic, manifesting itself in fractured relationships between individuals, groups, communities, societies, and nations. This, we argue, is the essence of social exclusion. ${ }^{34}$ In writing about transformative relationships in protracted internal and internationalized conflict-contexts that produce refugees-Mennonite scholar and practitioner John Paul Lederach emphasizes the "interdependence between various levels of society affected by and affecting change processes." 35 Thus, a system-change model of integration involves transformation at all levelspersonal, relational, institutional, and cultural. ${ }^{36}$

Seeing integration, or inclusion, as conflict transformation, or system change, is uncommon in refugee-receiving 
countries in the Global North. ${ }^{37}$ The social and legal environments of host nations are relatively just and fair, compared to refugee source countries, and by virtue of offering safety and protection, a national moral superiority is implied. Furthermore, this narrow perspective denies the inextricable ties between "refugee-producing" and "refugee-saving" nation-states, and the incessant historical practices that give rise to collective violence and "populations that have experienced a deep fracture in human relationships as a result of fundamental violations of their human rights." ${ }^{8}$ Especially in the relationships of refugee sponsorship, system change is a demanding point of view, as a critical gaze must be turned to the self and the Other in social and historical relations of power. To recognize the sustained conflict and slow violence of "soft domination" 39 requires eschewing common sense binaries to, instead, hold paradox.

Some definitions of terms are required. According to French sociologist Pierre Bourdieu, the social world is made up of multiple and diverse social fields and subfields, or arenas of contest and struggle. $4^{\circ} \mathrm{A}$ social field, analogous to a field of play in a highly competitive game of sport, is defined by its structure of capital, both material and symbolic, as individuals and groups compete for available resources that are effective and valued in that social field. All social space is ordered according to the legitimate means of appropriating and circulating capital, and the resulting structure and volumes possessed by individuals and groups engaged in any given social field. Occupants of various positions in social fields "seek, individually or collectively, to safeguard or improve their position." ${ }^{41}$ In other words, a particular disposition, or habitus, is associated with advancement in this social field, with the accumulation of various species of capital. The habitus-much more than identity-is "socialized subjectivity" and "the product of collective and individual history," which is expressed through taste and disposition, or embodied habits that are adjusted to social economies in which we engage..$^{2} \mathrm{~A}$ divided habitus, or "coherent incoherence," 43 is a necessary "conciliation of contraries" 44 in response to competing social fields and structures of capital, and coincident and opposing positions (i.e., dominant and dominated) in each. We will draw on this tripartite concept in the analysis that follows.

\section{Methods and Methodology: A Case Study of MCC}

History of MCC and Canada's Private Sponsorship Model

Mennonite Central Committee (MCC) was founded in 1920 when famine and the decimation of Mennonite communities in Ukraine during the Russian Revolution stirred Mennonites in North America to respond to the need of their co-religionists. ${ }^{45}$ In addition to aid, resettlement to Canada was an important aspect of the work of the newly formed organization. ${ }^{46}$ Between 1923 and 1930, Canada accepted over 21,00o Mennonites from the Soviet Union, with the understanding that Canadian Mennonite communities would provide for and resettle these newcomers. In the following decades, MCC expanded its relief and international development work well beyond assistance to fellow Mennonites. ${ }^{47}$ According to William Janzen, a long-time director of MCC Canada's (MCCC) Ottawa office, the historical experience of MCC in refugee resettlement served as a precedent for Canada's Private Sponsorship of Refugee (PSR) Program, which was established more than fifty years after MCC was established. $4^{8}$ Janzen also served as one of the negotiators of Canada's original Master Agreement, which MCCC signed in 1979. This agreement with the federal government provided the legal basis for MCCC to work with local congregations that, in turn, offered organizational and logistical support for groups of citizens to privately sponsor refugees. MCCC has sustained a vibrant refugee sponsorship program among Mennonite churches for forty years.

Today MCC defines itself as "a worldwide ministry of Anabaptist churches," with national offices in both Winnipeg (Manitoba) and Akron (Pennsylvania), enabling congregations to become engaged in "relief, development and peace in the name of Christ" 49 at home and abroad.

MCC provides a longstanding and unique case example for considering the relationships of private sponsorship in Canada for at least four key factors: its origins in providing aid to refugees; its role in Canada's private sponsorship program; its ties with Mennonite and Anabaptist churches and their refugee heritage; and the sustained engagement of individuals, sponsorship groups, and sponsoring congregations in private sponsorship.

\section{Research Methods}

This analysis emerged from a qualitative research partnership between MCC Ontario (MCсо) and York University. Our study used a reflexive community-based framework, whereby the research purpose, question, design, and data generation were collectively formulated and conducted in a partnership between researchers at York University, the MCCO Refugee Sponsorship and Settlement Associate, and the MCCO refugee program coordinator. The objective of this study was to examine how the relationships and practices within MCCC's private sponsorship program invigorate or frustrate dynamics of social inclusion.

Qualitative data were gathered in 2018 through seven focus groups with five to eight sponsors each, totalling fortynine participants from twenty-one churches in six geographical regions that sponsored refugees through MCC Ontario between 2007 and 2015; seven interviews with seventeen former refugee newcomers who were sponsored by one of 
the sample groups; ${ }^{\circ 0}$ a key informant interview with Brian Dyck, the National Migration and Resettlement Program coordinator; and MCC documents and publications. None of the sponsorships were named cases, but rather the sponsored individuals and families were identified through the Visa Office Referred (vor) or Blended Visa Office-Referred (BVOR) Program. This is significant for the purposes of our study, since sponsors had no prior relationship with the refugee newcomers they sponsored. Apart from one sponsoring church that was affiliated with the Evangelical Missionary Church of Canada, all congregations within the sample were members of Mennonite denominations that are formal contributing constituents of MCCC, with the majority belonging to the Mennonite Church..$^{51}$ MCco staff used its database to identify sponsors across Ontario and provided formal invitations on behalf of the organization. Because a primary objective of the research was to understand the nature and development of sponsorship roles and relationships over time, the sample of CGS was limited to those who had sponsored a family or individual prior to the 2015-16 Syrian resettlement efforts. Contact information for CGs before 2007 was limited, thus our sample captured sponsors between 2007 and 2015. However, as the data reveal, several congregations had been sponsoring for decades, even since 1979. A purposive sample of these long-standing groups that had engaged in multiple sponsorships prior to 2015 was selected from regions in Ontario with the largest representation of these groups: Waterloo Region, Stratford, Niagara, and the Greater Toronto Area. Aiming for multiplicity of perspective, purposive sampling was further employed to add three additional focus groups: (1) sponsors from the Leamington area, to provide a rural perspective; (2) sponsors from Ottawa Mennonite Church, to understand the experiences of the longeststanding CG with the most completed sponsorships; and (3) a CG comprising individuals who attended two different Mennonite churches and were sponsored through MCCC but independent of either congregation. Subsequently, sponsors extended the invitation to participate to those whom they had sponsored, resembling a purposive snowball sampling method, as recruitment was limited to former refugee newcomers with whom sponsors had an ongoing relationship. Refugee countries of origin represented included Iraq, Syria, Eritrea, South Sudan, and Colombia. Interpreters were used for four of the seven newcomer interviews, for Arabic, Tigrinya, and Spanish.

Focus group discussions and interviews were audiorecorded and transcribed. Discussions with sponsors centred on the following topics: expectations or goals of sponsorship, values and guiding principles of sponsorship, shifting and growing relationships between sponsor and sponsored refugees over time, best practices, and personal experiences of sponsorship. Demographic information for each focus group participant was collected prior to each focus group. Thematic analysis of the focus group data was conducted through a collaborative and iterative approach, combining independent analyses by authors Enns and Good Gingrich, and collaborative analysis with MCCo program coordinators. Direct quotations from former refugee newcomers ${ }^{52}$ are identified with pseudonyms, and those from sponsors with the number of the focus group.

\section{A Reflexive Lens}

Research and practice that adopt a relational and systems framework are necessarily reflexive. In other words, the focus of attention is on the ways in which we engage with one another, as well as the outcomes of our work together. We identify the overarching methodology that guided this research project as "epistemic reflexivity." 53 Bourdieu's practice of reflexivity entails the systematic analysis of practice in everyday social relations, "the objective archeology of our unconscious," and the arbitrary. ${ }^{54}$ Reflexive sociology "is critical of established patterns of power and privilege as well as of the politics that supports them." 55 More simply, a reflexive analysis shifts our gaze. Rather than the conventional focus on excluded individuals or groups-the Other-who are the targets of policies and services to help them become included or integrated, we take as our object of study the social spaces that comprise this largely uncontested "centre," specifically, the institutional and interpersonal relationships of private refugee sponsorship: a primary objective is "to historicize and so denaturalize that which seems most natural in the social order," to the point of seeming inevitable. ${ }^{56}$ Epistemic reflexivity requires us to see what we take for granted, to recognize that we have a world view that is not the only way to view the world.

\section{Institutional Relations: The Nested Social Fields of Refugee Sponsorship}

As for all social fields, the institutional relations of private sponsorship are arenas of contest and struggle. Specifically, MCCC has a duty through its sponsorship agreement to function as an extension of the federal government (IRCC) in carrying out the directives of the PSR Program. Yet equally important in our case example is MCCC's obligation to its constituency of Mennonite and affiliated congregations. Thus, MCCC is answerable to two distinct constituencies and systems of institutions, policies, and practices. As a broker between government directives and sponsors, MCCC must hold in tension two conflicting sets of values, or structures of capital. We will explore the institutional and interpersonal implications of these contradictory social fields and structures of capital in the following sections. 


\section{The Market-State Social Field}

With its primary purpose of refugee settlement, Canada's PSR Program fits within the social welfare arm of the nation-state. Yet private sponsorship programs do not fall neatly under one of the four sectors commonly associated with national welfare states: government (or public), market (or private for-profit), community/voluntary sector (private not-forprofit), and family (private and informal). The "settlement and integration of PSRS" is to be achieved through a "partnership of support" from informal civil society (sponsorship groups) and publicly funded Service Provider Organizations (sPos). 57

Canada's PSR Program is designed to be a public-private partnership, but direct service provision and a portion or all of the cost is delegated to the formal not-for-profit community/voluntary sector as well as informal family and civil society, yet the state imposes the legal framework and practice regulations. This is a double privatization, as the marketized public transfers international and domestic responsibility to both the formal and informal not-for-profit private sectors, blurring multiple boundaries within and beyond the nation-state.

The logic or structure of capital of the PSR Program is made explicit in its goals, the terms for "success," and what sponsors are "to make/to do." 58 Even a cursory glance at IRCC guidelines and instructions for sponsors reveals that the standard for successful private sponsorship is measured primarily by a particularly narrow version of self-sufficiency of refugee newcomers at the end of the one-year sponsorship. In practice, whether defined as settlement, integration, or inclusion, the outcome is most often assessed through individual and static indicators of financial independence and/or an emotional sense of belonging and trust. Market logic assumes that the subjective and material realities of social exclusion are best addressed through paid work. Such person-change measures constitute enforced dependency on the market. This is social exclusion by design, as we know that inclusion is not available for everyone through paid work.

\section{The Mennonite/mCC Social Field: A Countercultural System of Capital}

Despite a range of personal beliefs and contradictory expressions of proximity or distance to religion and the Mennonite church, a common sponsorship ethos, or structure of capital, runs through official MCC discourse and all participant responses. This ethos is institutionalized in MCC and its constituent churches and is reinforced in the specific practices of synergy that are mutually productive for Mennonite organizations, MCC programs, and participating individuals.
We have argued elsewhere that MCCC has maintained a commitment to refugee sponsorship largely as the result of historical beginnings steeped in refugee resettlement, its local and national credibility as a SAH, its substantial presence and history in international development work, and its structure and grassroots connections with Mennonite and affiliating denominations in North America. ${ }^{59}$ Consequently, we theorize this diverse yet singular social context as a social field, with its own "institutional boundaries," "barriers to entry," and "specialists in the elaboration of a distinctive source of authority and sociodicy." 60 As with all social fields, the Mennonite/MCC social field functions according to its own discernible structure of capital that cuts across place and time and directs the accumulation and exchange of material and symbolic assets, and produces a particular habitus or disposition.

We identify the following distinct features of the Mennonite/MCC social field that have supported and sustained a unique model of refugee sponsorship with long-standing sponsoring groups for over forty years.

\section{A Heritage of Persecution}

Mennonite identity is steeped in "refugeeness." The MCC disposition, or habitus, is rooted in stories of Mennonite refugees from the twentieth century. Janzen and Epp-Tiessen identify the significance of an inherited refugee story, most importantly flight from the Soviet Union during and after the First and Second World Wars, in motivating Mennonites to become involved in the sponsorship of Indo-Chinese refugees. Epp-Tiessen explains: "They, their parents, or grandparents had been refugees, and they now wished to ease the suffering of others." ${ }^{11} \mathrm{~A}$ familiar and inspiring grand narrative is the almost 400-page first-hand account of MCC's second refugee resettlement effort of 12,000 uprooted Mennonites from Russia to South and North America from 1941 to 1949 , as told by lifelong MCC workers and Canadian Mennonites Peter and Elfrieda Dyck (1991). The title, Up from the Rubble: The Epic Rescue of Thousands of War-Ravaged Mennonite Refugees, contains the essence of this legendary David and Goliath story.

Nearly half of the sponsors in our study articulated a familial refugee story. This sense of personal connection to "refugeeness" was repeatedly identified as a motivating factor for sponsors: "I think one of the reasons that I feel strongly about this is that my parents were refugees after the Second World War." 62 Some respondents described a direct and intimate relationship with MCC, as they associated their current life in Canada with the support and aid provided by MCC when they themselves, or their family, resettled in Canada as refugees. When asked why they chose to sponsor through MCC, an older couple noted, "When we talk about our family 
experience, it was MCC who was there, and they found sponsors for my parents and they found sponsors for [my wife] and family. The natural choice." 63

While not all North American Mennonites reference a familial refugee past from the twentieth century, the Mennonite heritage and collective identity also draws from stories of sixteenth-century Anabaptists, who were persecuted for opposing the religious and political leaders and institutions of the day. The Anabaptist disposition is countercultural, even radical, outside the mainstream and inclined toward the margins. Mennonites often use this history to identify with the disadvantaged and powerless, as social and cultural capital-far more important than material capital in a Mennonite social field-is associated with (triumph over) oppression and suffering. This "posture" for the dispossessed and the outsider has shaped the particular Anabaptist/Mennonite interpretation of biblical teaching and theological explanations for MCC's vision and mission of "serving with humility and in partnership to meet local needs with local solutions" and "to prevent violence and promote peace and justice." 64

\section{A Culture of Beliefs in Action/An Ethos of Sponsorship}

A practical and collective response to human crisis or need is an obligation that grows out of religious and humanitarian beliefs and values that have shaped Mennonite cultures for over 500 years. For focus group participants who articulated a refugee past, sponsorship was clearly expressed as a means to strengthen their Mennonite identity by weaving this heritage with their current practice. Some also drew on classic formulations of Anabaptist/Mennonite theology to explain their motivation to sponsor: "Our congregation is very influenced by Anabaptist theology. Specifically, we recognize the call of the gospel to make a difference in the world and discipleship and service, so the thrust of our service is that we want to reach out to some of these people globally that are in stressed situations." 65 Discipleship, central to Mennonite theology and culture, emerged as an important element for some sponsors who specifically described sponsorship through MCC as "an extension, a practical part of [Mennonite] faith" 66 and of "loving mercy and acting justly" 67 One respondent from a congregation in southern Ontario with a long history of sponsorship noted that refugee sponsorship is a "Christian service," and there "seems to be this understanding that within the call to discipleship we should be doing something, and we do this." ${ }^{\prime 6}$ Although all respondents had some affiliation with a Mennonite church or heritage, several explicitly articulated that their involvement in sponsorship was not tied to faith: "The fact that we can do it is why we did it. Not out of any obligation, out of any faith, or anything else. It was just that we had the means, and therefore we could participate." 69 For these sponsors, MCC's "theological hands-off" stance made it possible to participate in "a handson, real thing-it's not just talking about it.... This is real. I can contribute to making a real difference, a meaningful difference." 70 For Mennonites in Canada, whether claiming religious affiliation or not, sponsorship through MCC gives expression to a past refugee experience, a current representation of triumph over hardship, and a sustained collective identity as people of peace. In turn, a unique MCC sponsorship ethos is reinforced.

\section{A Community of Sponsoring Communities}

MCC's structure expresses an organizational commitment to "relationships with our local partners and churches"71 that is consistent with Anabaptist principles of community, mutual aid, and sharing of material and social resources. The church as a faith community provides a natural structure and culture for sponsorship. A prominent theme in focus group discussions was the mutually supportive and constitutive relationship - an institutional synergy-between MCC and affiliated churches. Congregations that have maintained a long-term engagement in private sponsorship are heavily reliant on MCC, its structure, reputation, and staff support. In turn, the stability of MCC's refugee program is owed to the sustained engagement of individual congregations. The tight connection between Mennonite churches and MCC was articulated by a focus group member: "Our churches are all part of MCC, we are constituents of MCC-we see MCC as the extension of our local congregation that does the local and international relief and development work and MCC as an extension of the community and development work."72

In addition to the reputation and practical support of MCC, long-standing congregational structures, practices, and relationships offer the material, social, and symbolic resources necessary for refugee sponsorship. Local congregations are an established collective of people who provide financial and in-kind resources, form sponsorship groups, replace group members as necessary, generate additional supports and resources, connect with community networks, and have ready access to a physical space to hold events or meetings. Many churches have designated funds for refugee support in the form of mission budgets, benevolence funds, or even a designated budget line specifically for refugee resettlement needs. Further, the congregation provides a financial and social safety net, a pool of potential resources.

Furthermore, MCC's extensive international development work and the involvement of North American Mennonite churches has cultivated institutional and interpersonal relationships that extend across place and time. MCC has programs in fifty-six countries and is involved in another ten countries, with 1,118 workers around the world, ${ }^{73}$ and 
depends on both local staff and a substantial contingent of North American Mennonite volunteers to implement its international programs. With its unique capacity to provide accessible and popular international programming that grows a community of returned alumni-known as "MCCers"-MCC's international work is infused into local congregations through interpersonal relationships. The high number of refugees sponsored from specific countries (e.g., Colombia, Palestine) reflects MCC's long-term and trusted relationships with international and local partners in those countries, including churches, governments, service organizations, and communities.

\section{Peacebuilding}

A centrepiece of Anabaptist/Mennonite theology and tradition is pacifism, or non-violent resistance. Similarly, MCC values initiatives that encourage "relationship-building as peacebuilding." 74 MCC views sponsorship through this peace lens, and hopes for "transforming and everlasting" relationships, ${ }^{75}$ particularly between people of different faiths and cultures. Writing as an employee of MCC, Stephanie Dyck states that MCC encourages sponsors to "move to deeper levels of engagement" with newcomers to encourage a "mutually transformative process of integration and community building." 76 While much of the material on successful sponsorship of refugees emphasizes self-sufficiency and independence, MCC's focus on mutually transformative relationships is somewhat unusual in the world of refugee sponsorship. For example, unlike many saHs that select refugees to sponsor through named cases, MCC is committed to meeting the resettlement needs of any refugee, regardless of religion or culture. 77 This was a deliberate decision made after a review of the sponsorship program in 2008 , when MCCC stipulated that at least 60 per cent of all cases were to be referred by UNHCR or the Canada Visa Office in order to prioritize those who had been identified as most in need. Further demonstrating this commitment, MCCC resettled approximately one-third of all refugees identified for resettlement by UNHCR in $2017^{78}$

MCC's goal of relationships of mutual transformation appears in various organization documents and repeatedly came up in conversation with staff during the course of our research. Dyck asserts that sponsorship can promote "mutually transformative relationships."79 Although the term defies definition, it is clear that the ideal of transformative relationships as an objective of sponsorship emphasizes relationships over belief and goes beyond the utilitarian roles and expectations commonly associated with newcomer integration. Whereas MCCC may mark "successful" sponsorship with economic independence of the refugee newcomer family, a hope for long-term reciprocal relationships is an additional and equally valued ideal, producing a split in the habitus in Mennonite sponsoring relationships.

\section{Refugee Sponsorship: An Arena of Contest and Struggle}

From a relational and reflexive point of view, the dynamics of social exclusion and inclusion produced in the private sponsorship of refugees are directly tied to the nested social fields, their operating structures of capital, and associated positions and dispositions of the sponsor in relation to the Other. The conflicting structures of capital of the Mennonite/MCC and market-state social fields introduce complexities, tensions, contradictions, and possibilities for a range of positions and dispositions in the sponsoring relationship and practices that both promote and obstruct social inclusion.

\section{The Divided Habitus of Mennonite Sponsorship}

The identities and roles afforded refugee newcomers in the sponsorship relationship and beyond have recently been examined. For example, Kyriakides et al. draw on Said's theory of Orientalism to argue that the refugee, as "nonWestern other," is constructed as "uncivilised, unruly, and lacking in cultural sophistication," 80 thus rendering "our' Western morality and civilization." ${ }^{11}$ Alternatively, humanitarian views of the refugee subject emphasize the suffering and hardship experienced by "undifferentiated masses" of refugees and asylum seekers, framing the character of the refugee in a positive light, but without agency. ${ }^{82}$ Similarly, Kyriakides et al. focus attention on "representations of passivity and infantilization which must be negotiated as part of the resettlement experience." ${ }^{3}$ The refugee as deviant, ascribed low power and low value, ${ }^{84}$ is easily turned to threat. In contrast, the refugee as passive victim is deemed a worthy recipient of aid and support.

In the context of the sponsorship relationship, the ascribed identities of the refugee newcomer have everything to do with the disposition, posture, and (imagined) identity taken up by the sponsor. A focus on the Other as the object of study and site of intervention constructs certain configurations of "them," but more importantly, assembles an idealized "us." The refugee as threat, which Winter and colleagues point out is common in social and news media, feeds a collective illusion of vulnerability, even victimization by the undefined Other. ${ }^{85}$ In the sponsoring relationship, this duality is unlikely, as the undeserving refugee justifies avoidance of engagement, withholding of support, or even punishment and retaliation. In contrast, however, the constructed identities of humanitarian discourse fit nicely within the sponsorship relationship, as the "passive 'them"' positions the sponsor as the "agentic "us." 86 The natural disposition of the sponsor in relation to the refugee newcomer in need 
of a humanitarian response is one of "helper" or "protector," which, as Kyriakides et al. imply, reinforces a good deal of social distance and a hierarchical order of things. The helper habitus is inclined toward a person-change approach to refugee newcomer integration.

These positions and dispositions-commanding helper and passive victim-seem natural, especially in the early days of settlement. The sponsoring relationship was reported by both sponsors and refugee newcomers to be primarily utilitarian for the first six to eight months, assisting newcomers with the basics of everyday life as outlined by MCCO, such as financial, health, housing, education, shopping, and transportation. ${ }^{87}$

Humanitarianism also encourages sponsors to "put themselves in the shoes' of people coping with difficult situations." 88 This position and disposition, contrasting the helper habitus, brings the self into full view. Mennonite sponsors were particularly inclined toward this "alongside" position. One sponsor illustrated how the refugee history had been absorbed into his own identity as a Mennonite and how the story of "the refugee" had become his own story: "Many of us came from refugee families ourselves, as Russian Mennonites, and that story resonates especially strongly with me. My parents were both victims of violence and [witnesses to] murder in Russia and then came here as refugees, and their story became my story." ${ }^{9} 9$ Similarly, one respondent felt connected to the past work of MCC and believed he was continuing a tradition of helping others: " $[\mathrm{MCC}]$ is still there, and I can tell this Muslim family, 'The same organization that helped my ancestors come to Canada, now helps you, and it has been around a long time."'90 For these individuals, sponsorship offers a means to engage in the work of MCC to give back to an organization from which they themselves, or their ancestors, had personally benefited. Even though still rooted in humanitarianism, this sponsor disposition is distinct from both the masterful "helper" and the compassionate "protector," as the identification of the self with the Other collapses social distance. The pretence of sameness suggests an ambivalent disposition and position in relation to the refugee newcomer, because only the sponsor is afforded the capacity to take on and discard "refugeeness" and the associated symbolic power at will.

Sponsoring relationships evolve, often moving from more immediate and practical concerns to emotional and social supports. Imposing the helper disposition into more personal aspects of life, some sponsors aspired to direct the decisions of newcomers, "to make them good, Canadian citizens." ${ }^{91}$ Ideas of citizenship were associated with learning English, finding employment, and becoming "contributing members of Canadian society." 92
Both sponsors and former refugee newcomers related encountering uncertainty, disappointment, and frustration. Revealing some coherence with the dominant market-state social field, sponsors' efforts toward person-change integration-defined for and practised to the refugee newcomer ${ }^{3}$ sometimes backfired. For example, sponsors described using their time and social resources to find potential employment options for newcomers, efforts that were ignored or rejected. One respondent lamented, "Part of this makes me angry, like they're milking the system-this bothers me.... We're trying to be helpful and they're not really willing to do their end of the bargain."94 Shifting the locus of control, the newcomers who reported having a sustained job and were satisfied in their line of work had ultimately settled on employment that they had sought and secured on their own accord. For many newcomers, the "survival jobs" available to them could not replace the livelihoods they left behind. Nicolas commented that his occupational background was "useless" in Canada and explained how he was struggling with finances: "I can't stop. There are no savings, no safety net." As commonly reported in previous research, our data indicate that newcomers continue to encounter barriers to dignified employment, even years after resettlement.

The complicated nature of sponsorship relationships was defined by one sponsor as a "tension between wanting to help and wanting to not help too much." 95 Most sponsors asserted that newcomers should become independent, and many noted certain times when they felt newcomers should "make their own way in life." 96 Revealing an ambivalent disposition, or divided habitus, many sponsors expressed a desire or expectation for their relationships with the refugee newcomer to extend beyond the sponsorship year, noting that "successful [sponsorships] are the ones where there have been positive relationships established and maintained." 97 In some instances, the objective of "independence" was overshadowed by the desire to maintain close relationships. For example, sponsors recognized their involvement might do newcomers a "disservice" 98 and have direct impact on their independence. To enable newcomers to learn and make decisions themselves required sponsors to back off: "I think for some committees, they [refugees] almost become like children and so they're very happy when the sponsorship groups make decisions for them, [but] for me, the goal was independence-to make myself redundant as quickly as possible." 99 Extending the helper-helped dispositions well beyond the sponsoring year, sponsors reflected the need to strategically position themselves in the relationship so they do not abandon the newcomer, but also do not create new relationships of dependence. This framing largely assumes that sponsors are the ones who are both providing 
independence and standing in the way of it - that they alone bear this responsibility.

Encouraging an alternative sponsor position and disposition, a valuable role identified by former refugee newcomers was that of simply listening-as Tiffany said, to "listen to the needs of the person they're taking care of" and "be patient," because newcomers "know things" but may find it difficult to express themselves, or as Ayah said, "to talk to us, to feel comfortable." Although sponsors readily fulfilled their utilitarian responsibilities, few recognized this more passive role and disposition, to simply visit with the family and to learn "what's important to them.... We think that we know what is the best way to do things, but sometimes you really have to listen to them and let them do what they think they have to do." 100

Staying with the helper-helped dyad, yet expressing a shift in the sponsor disposition, it was noted that a certain amount of advocacy is necessary for the utilitarian responsibilities of sponsors, such as facilitating access to medical and education systems. The objective of advocacy was often identified as negotiating adjustment in the interaction between the individual and institution rather than individual-level change, thus bringing the social context into view. Adopting a reflexive point of view and extending the line of vision even further to include the self in social relations, sponsors also described recognizing and using their personal privilege and influence to challenge the institution itself. Indeed, sponsors noted advocating for change within their own congregations and larger communities in order to shift the narrative on refugee issues and dispel myths that fed xenophobia: "People have this notion that refugees are given tons and tons of money, more than anybody else.... When I see something like that and I say, 'This isn't true, check your facts-don't go spreading false rumours about what's happening.... You gotta give your head a shake and speak up." ${ }^{101}$ This recognition of relative privilege - not by virtue of personal merit but due to uneven social relations in Canadian institutions and communities-shifts the emphasis from person change to system change.

As responsibilities officially end come "month 13," there is a need to redefine and reshape the sponsorship relationship. The majority of sponsors and newcomers described their ongoing relationships in familial terms, and in some respects, the use of familial words legitimizes the continuation of the sponsorship relationship. With an average age of sixty-five among the sample's sponsors, many noted that they considered themselves parents to many of the newcomers. Nearly all newcomers at some point referred to sponsorship members in relation to family. Hassan commented, "The sponsorship group is my family. All of them, because they help me to understand the future." Omar explained, "Until today, we still communicate and we still get together every once in a while, and we just became a small family. Or, I should say, we added to their big family." Omar's self-correction highlights contradictory meanings of these familial relationships, as sponsors incorporate new members into their existing families and lives, while newcomers are forced to begin their lives in Canada from experiences of loss. As Dhalia said, "They were our family, we had nobody here."

MCC encourages "mutually transformative" relationships that continue beyond sponsorship, facilitating the shift "from sponsorship to [interpersonal-change] integration." ${ }^{102}$ Navigating this transition from an uneven relationship bound within the duties of one year to that of "mutual transformation" post-sponsorship, is paradoxical, introducing tensions and conflicts-and possibilities-in practice. The divided habitus, an expression of congruence to multiple positions and the divided self, allows for paradox to be contained dividing practices in the market-state field to be subverted. ${ }^{103}$ The cleft habitus- "to step into one's authority while remaining ever mindful of its limits and offences"104_opens the possibility to look beyond person-change integration, to interpersonal change, place change, and perhaps even system change.

\section{Institutional Tensions, Contradictions, and Possibilities}

Distinctions between MCc's international and domestic programs (especially the refugee sponsorship program), particularly vis-à-vis the ideal of mutually transformative relationships in practice, highlight tensions and contradictions in the Mennonite/MCC social field. Specifically, MCC's operating principles and institutional theory of change, articulated in a brief internal document, "encapsulate MCC's conviction that lasting change often requires long-term commitment and happens when all members of a community connect across lines of difference to actively participate in shaping and implementing visions for just social, environmental, and economic structures." 105 Following the example of Jesus, and working in partnership with local organizations and communities, "unjust systems that oppress and exclude" are transformed to "just economic relationships," "conflict" into "relief and development work," and "structures of injustice and their legacies" to "a just peace." 106

In its more prominent international relief and development work, MCC does not enter into agreements with foreign governments as is required for the refugee sponsorship program in Canada. As a result, MCC is freer in its overseas work to contest governments, policies, and local practices, and "to engage in community-based efforts and public policy advocacy at local, national, and international levels that build durable peace." ${ }^{107}$ Unlike the international contexts in which MCC engages, little emphasis is placed on transformation of 
unjust social relations in Canada, suggesting an institutional bifurcation between the need for transformation of communities, institutions, and economic systems at home and abroad. Further, despite Mcc's focus on "the radical transformation of unjust systems" in its international programs, MCC staff and sponsors rarely identity or address refugee newcomer experiences of social exclusion in Canada. A personal and institutional reluctance to recognize uneven power relationships in our own backyard is revealed. Ironically, reflexivity - to see the self and the Other in social and historical relations of power-is resisted in refugee sponsorship. Yet the shared principles of relationship-building and practical engagement are given expression and reinforced through MCCC's refugee sponsorship program.

\section{Conclusions}

We return to our guiding research objective: to examine the ways in which MCCC's private sponsorship program invigorates or frustrates dynamics of social inclusion. The settlement experiences articulated by former refugee newcomers in our study expose stubborn dynamics of social exclusion, mingled with genuine experiences of social inclusion. This is the paradox-the simultaneous gain and loss-of forced migration and settlement. Former refugee newcomers expressed their appreciation for the hands-on, practical support they received from sponsors: Nicolas commented, "People who arrive with the help of the Mennonite [church] or with churches with programs like that arrive with a huge blessing. It's a big help." Other newcomers recalled being pleasantly surprised by how they were received. Fatimah stated, "I did not expect such treatment. I had never seen that kind of kindness and hospitality before."

However, the everyday lives of refugee newcomers continue into "month 13" and beyond, long after the contrived relationships of sponsorship end. Even the sustained relationships of some sponsorships could not shield the ways in which communities and institutions function to keep people marginalized. The persisting and intersecting dynamics of social exclusion experienced by former refugee newcomers included economic exclusion, or loss of livelihood and meaningful work that is commensurate with acquired education and skills; spatial exclusion, or isolation and loneliness compounded by segregation in one neighbourhood, apartment building, or high school; socio-political exclusion, or barriers to accessing informal and formal social supports, such as health care, education, even friends beyond the sponsorship group; and subjective exclusion, or discounted classification, to find oneself "boxed up," defined by and for others as only refugees, as only vulnerable, as only needy. ${ }^{108}$ The systematic devaluation of education, knowledge, and expertise for newcomers-even when they are no longer newcomers-in
Canada's labour market and local communities is well documented. Subjective exclusion functions over time. This is the dispossession of symbolic capital, and it works to keep people in disadvantaged positions.

The Mennonite/MCC social field and structure of capital generates tensions and contradictions. Yet this uncommon sense resists the common sense individualized perspective that limits integration to person change, thus presenting possibilities for seeing, understanding, and challenging processes and outcomes of social exclusion. The invisible yet idealized subject and "centre" of person-change integration is brought into view from a position and disposition outside. Yet in the context of the PSR Program in Canada, identification with the Other without a reflexive view of the self in social relations of power is disingenuous and unstable. Furthermore, well-meaning efforts to change or support the excluded individuals, while overlooking the processes that make them excluded, ultimately serve to reinforce long-standing social and economic divides. Social inclusion requires us to reverse our gaze-to examine and confront the assumptions we hold and everyday practices in which we engage that prop up our undeserved places and identities of privilege.

\section{Notes}

1 Good Gingrich and Enns have no current or past formal relationship with MCC Canada or MCC Ontario. Both authors are associated with the Mennonite community and culture by ethnicity, with differing relationships with the church. We would like to thank Kerry Fast for her editing and consulting assistance. Her expertise in developmental editing and her past involvement in MCCC's refugee program helped shape this article.

2 Mennonite Central Committee Canada, An Introduction to Southeast Asian Refugees and Suggestions for Sponsors (Winnipeg, MB: MCCC, 1979).

3 Refugee Sponsorship Training Program, "The Private Sponsorship of Refugees (PSR) Program," http://www. rstp.ca/en/refugee-sponsorship/the-private-sponsorshipof-refugees-program/.

4 Refugee Sponsorship Training Program, "The Private Sponsorship of Refugees (PSR) Program."

5 Government of Canada, "Resettlement in Canada as a Refugee," last modified 17 September 2018, https://www. canada.ca/en/immigration-refugees-citizenship/services/ refugees/help-outside-canada/private-sponsorshipprogram.html.

6 Refugee Sponsorship Training Program, "Responsibilities of Sponsorship Groups \& Availability of IRCCFunded Resettlement and Settlement Services," Immigration, Refugees and Citizenship Canada (IRCC)," May 2017, http://www.rstp.ca/en/resources/ircc-resources/ 
responsibilities-of-sponsorship-groups-availability-ofircc-funded-restlement-settlement-services/.

7 Immigration, Refugees and Citizenship Canada, The RSTP Handbook for Sponsoring Groups, "Chapter 8: The First Year and Beyond," 2019, http://www.rstp.ca/en/resources/ hand-book-for-sponsoring-groups/.

8 Immigration, Refugees and Citizenship Canada, RSTP Handbook.

9 See Thea Enns, Luann Good Gingrich, and Kaylee Perez, "Religious Heritage, Institutionalized Ethos, and Synergies: Mennonite Central Committee and Canada’s Private Sponsorship of Refugees Program" (paper presented at "Private Refugee Sponsorship: Concepts, Cases and Consequences," Munk School of Global Affairs, University of Toronto, October 18-19, 2019).

10 The research reported in this article is part of a larger project that aims to measure processes and outcomes of social exclusion and inclusion for immigrant and refugee newcomers in Canada. The authors gratefully acknowledge the funding support of the Social Sciences and Research Council (ssHrc) of Canada through the Insight Grant entitled "Advancing Social Inclusion in Canada's Diverse Communities: Neighbourhood, Regional, and National Comparisons," PI Luann Good Gingrich.

11 Geoffrey Cameron and Shauna Labman, "Private Refugee Sponsorship: An Evolving Framework for Refugee Resettlement" (paper presented at "Private Refugee Sponsorship: Concepts, Cases and Consequences," Munk School of Global Affairs, University of Toronto, October 18-19, 2019)

12 Government of Canada, "Private Sponsorship of Refugees Program: Sponsorship Agreement Holders," 15 January 2019, https://www.canada.ca/en/immigration-refugeescitizenship/services/refugees/help-outside-canada/privatesponsorship-program/agreement-holders/holders-list .html.

13 Judith Kumin, Welcoming Engagement: How Private Sponsorship Can Strengthen Refugee Resettlement in the European Union, Migration Policy Institute Europe (December 2015).

14 Cameron and Labman, "Private Sponsorship of Refugees Program," 10.

15 See Jennifer Hyndman, William Payne, and Shauna Jimenez, "Private Refugee Sponsorship in Canada," Forced Migration Review 54 (2017): 56-9; Shauna Labman, "Private Sponsorship: Complementary or Conflicting Interests?" Refuge 32, no. 2 (2016): 67-80; Michael Lanphier, "Sponsorship: Organizational, Sponsor, and Refugee Perspectives," Journal of International Migration and Integration 4, no. 2 (2003): 237-56; Barbara Treviranus and Michael Casasola, "Canada's Private Sponsorship of Refugees Program: A Practitioner's Perspective of Its Past and Future," Journal of International Migration and Integration 4, no. 2 (2003): 177-202.

16 See Michael J. Molloy, Peter Duschinsky, Kurt F. Jensen, and Robert J. Shalka, Running on Empty: Canada and the Indochinese Refugees, 1975-1980 (Montreal and Kingston:
McGill-Queen's University Press, 2017); "The Indochinese Refugee Movement and the Launch of Canada's Private Sponsorship Program: Special Issue," Refuge 32, no. 2 (2016).

17 See, for example, IRCC, Evaluation of the Resettlement Programs (GAR, PSR, BVOR and RAP) (Ottawa: Immigration, Refugees and Citizenship Canada-Evaluation Division, 2016); Laura Simich, "Negotiating Boundaries of Refugee Resettlement: A Study of Settlement Patterns and Social Support," Canadian Review of Sociology and Anthropology 40, no. 5 (2003): 575-91; Lori A. Wilkinson, "The Integration of Refugee Youth in Canada" (PhD diss., University of Alberta, 2001), 13; Morton Beiser, "Sponsorship and Resettlement Success," Journal of International Migration and Integration 4, no. 2 (2003): 203-15.

18 Michaela Hynie, "Canada's Syrian Refugee Program, Intergroup Relationships and Identities," Canadian Ethnic Studies 50, no. 2 (2018): 1-12.

19 Audrey Macklin, Kathryn Barber, Luin Goldring, Jennifer Hyndman, Anna Korteweg, Shauna Labman, and Jona Zyfi, "A Preliminary Investigation into Private Refugee Sponsors," Canadian Ethnic Studies 50, no. 2 (2018): 35-57.

20 Macklin et al., "Preliminary Investigation."

21 Christine McKinlay, "Welcoming the Stranger: The Canadian Church and the Private Sponsorship of Refugees Program" (MA thesis, Ryerson University, 2008).

22 See Stephanie Phetsamay Stobbe, "Cross-cultural Experiences of Laotian Refugees and Mennonite Sponsors in British Columbia and Manitoba," Journal of Mennonite Studies 24 (2006): 111-28; Daphne N. Winland, "Christianity and Community: Conversion and Adaptation among Hmong Refugee Women," Canadian Journal of Sociology 19, no. 1 (1994): 21-45.

23 A variety of terms have been adopted to reference the target outcome of settlement policies and programs for immigrants and refugees, such as acculturation, adaptation, assimilation, integration, and inclusion. For an overview of integrationrelated terms, definitions, and debates, see Stephen Castles, Maja Korac, Ellie Vasta, and Steven Vertovec, "Integration: Mapping the Field" (Oxford: University of Oxford, Centre for Migration and Policy Research and Refugee Studies Centre, 2002); Jennifer Hyndman, "Research Summary on Resettled Refugee Integration in Canada" (Toronto: York University, Centre for Refugee Studies, 2011).

24 Hynie, for example, integrates the subjective considerations of belonging and security commonly associated with inclusion into her "holistic integration model (HIM)" to strengthen emphasis on the social context and "the nature of the relationships between refugees and other members of their communities" as well as "general community attitudes and beliefs about refugees." See Michaela Hynie. "Refugee Integration: Research and Policy," Peace and Conflict: Journal of Peace Psychology 24, no. 3 (2018): 265-6, 267.

25 Immigration, Refugees and Citizenship Canada, "Resettlement Services for Government-Assisted Refugees," last 
updated 21 January 2016, https://www.canada.ca/en/immigration-refugees-citizenship/news/2016/o1/resettlementand-settlement-services-for-government-assisted-refugees .html

26 See Luann Good Gingrich, Out of Place: Social Exclusion and Mennonite Migrants in Canada (Toronto: University of Toronto Press, 2016), 52-5.

27 Hynie, "Canada’s Syrian Refugee Program," 267. The idea of "two-way integration" has been taken up by governments in the Global North, including Canada, Australia, and across the Eu.

28 Hynie, "Canada's Syrian Refugee Program."

29 See, for example, Lara Winnemore and John Biles, "Canada's Two-Way Street Integration Model: Not without Its Stains, Strains and Growing Pains," Canadian Diversity/ Diversité canadienne 5, no. 1 (2006): 23-30.

30 Council of the European Union, Immigrant Integration Policy in the European Union (Brussels: Council of the European Union, 2004), 19.

31 Sally Lamping, Melissa Bertolo, and Tom Wahlrab, "Activist Citizens in an Immigrant-Friendly City: The Natural Helpers Program," Peace and Conflict: Journal of Peace Psychology, 24 (2018), 330-7.

32 Michaela Hynie, A. Korn, and D. Tao, "Social Context and Social Integration for Government-Assisted Refugees in Ontario, Canada," in After the Flight: The Dynamics of Refugee Settlement and Integration, ed. M. Poteet and S. Nourpanah, 183-227 (Newcastle upon Tyne, uk: Cambridge Scholars, 2016); Michaela Hynie, "Refugee Integration: Research and Policy," Peace and Conflict: Journal of Peace Psychology 24, no. 3 (2018): 265-76.

33 See, for example, Stephanie Dyck, "Private Refugee Sponsorship in Canada: An Opportunity for Mutual Transformation," Intersections: Challenges and Opportunities in Refugee Resettlement 5, no. 4 (2017): 13-14.

34 Good Gingrich proposes that social exclusion is, essentially, conflict that is manifested in processes and outcomes of economic, spatial, socio-political, and subjective divides. See Good Gingrich, Out of Place.

35 John Paul Lederach, "The Origins and Evolution of Infrastructures for Peace: A Personal Reflection," Journal of Peacebuilding \& Development 7, no. 3 (2012): 8-13.

36 For a useful discussion of conflict transformation, see John Paul Lederach, Preparing for Peace: Conflict Transformation across Cultures (Syracuse, NY: Syracuse University Press, 1995); John Paul Lederach, The Moral Imagination: The Art and Soul of Building Peace (Oxford: Oxford University Press, 2005).

37 Shifting the dominant vantage point of refugee integration from the Global North to the Global South, Kihato and Landau consider inclusion of (or by) place: Caroline Wanjiku Kihato and Loren B. Landau, "Stealth Humanitarianism: Negotiating Politics, Precarity and Performance Management in Protecting the Urban Displaced," Journal of Refugee Studies 30, no. 3 (2016): 407-25.
38 Adrienne Chambon, Susan McGrath, Ben Zion Shapiro, Mulugeta Abai, Teresa Dremetsikas, and Suzanne Dudziak, "From Interpersonal Links to Webs of Relations: Creating Befriending Relationships with Survivors of Torture and of War," Journal of Social Work Research 2, no. 2 (2001): 158.

39 Pierre Bourdieu et al., The Weight of the World: Social Suffering in Contemporary Society, trans. Priscilla Parkhurst Ferguson (Stanford, CA: Stanford University Press, 1999), 512.

40 Pierre Bourdieu, The Logic of Practice, trans. Richard Nice (Stanford, CA: Stanford University Press, 1990).

41 Pierre Bourdieu and and Loïc Wacquant, An Invitation to Reflexive Sociology (Chicago: University of Chicago Press, 1992), 101.

42 See Pierre Bourdieu, "Principles of an Economic Anthropology," in The Handbook of Economic Sociology, ed. Neil J. Smelser and Richard Swedberg (Princeton, NJ: Princeton University Press, 2005), 85.

43 Good Gingrich, Out of Place, 219.

44 Pierre Bourdieu, Sketch for a Self-Analysis, trans. Richard Nice (Cambridge: Polity, 2007), 112.

45 In October 1920 representatives from Mennonite churches in Manitoba, Saskatchewan, and Alberta met to organize a Canadian Central Committee similar to the Mennonite Central Committee just organized in the United States. The work of providing shelter and support for thousands of Mennonite refugees "until they were financially viable" prompted the formation of multiple Mennonite organizations, including the Canadian Mennonite Board of Colonization in 1922, the Mennonite Land Settlement Board in 1924, the Central Mennonite Immigration Committee (made up of Mennonite newcomers in Canada), and the Mennonite Central Relief Committee in western Canada. Esther Epp-Tiessen notes that "by the end of 1963, a wide representation of Mennonite and Brethren in Christ denominations had agreed to the transformation of their existing inter-Mennonite organizations into one new national entity known as Mennonite Central Committee Canada, with provincial counterparts." See Esther EppTiessen, Mennonite Central Committee in Canada: A History (Winnipeg: CMU, 2013), 71; Frank H. Epp, Mennonite Exodus: The Rescue and Resettlement of the Russian Mennonites since the Communist Revolution (Altona, MB: Canadian Mennonite Relief and Immigration Council, 1962).

46 William Janzen, "The 1979 mCC Canada Master Agreement for the Sponsorship of Refugees in Historical Perspective," Journal of Mennonite Studies 24 (2011): 211-22.

47 Sources: Epp, Mennonite Exodus; Jacob Gerbrandt, "Canadian Mennonite Board of Colonization," Global Anabaptist Mennonite Encyclopedia Online, last edited 18 July 2015, http://gameo.org/index.php?title=Canadian_Mennonite_ Board_of_Colonization\&oldid=132346.

48 Janzen, “1979 MCC Canada Master Agreement," 212.

49 For MCC's complete vision and mission statement, see MCC, "Vision and Mission," 2019, https://mcccanada.ca/learn/ about/mission. 
50 One interview with a former refugee newcomer/family was conducted in each of the six main focus group regions. Individuals and families were chosen on the basis of the overall diversity of the sample, considering factors such as family makeup, country of origin, and time of arrival. Seven separate interviews were conducted, comprising seventeen participants.

51 For a list of MCCC's sponsoring denominations, see "Leadership and Board," 2019, https://mcccanada.ca/learn/about/ leadership.

52 For the sake of brevity, and to highlight the identities of sponsorship relationships, former refugee newcomers or previously sponsored refugees are often identified as simply "refugees" or "newcomers." We recognize the symbolic violence of limiting the identity of sponsored individuals to refugees or newcomers, even years after resettlement.

53 For more on epistemic reflexivity, see Good Gingrich, Out of Place.

54 Pierre Bourdieu, Masculine Domination, trans. Richard Nice (Stanford, CA: Stanford University Press, 1998), 3.

55 Loïc Wacquant, "Pierre Bourdieu," in Key Sociological Thinkers, ed. R. Stones (New York: New York University Press, 1998), 217.

56 Bourdieu, Masculine Domination, 4.

57 Immigration, Refugees and Citizenship Canada, "Responsibilities of Sponsorship Groups \& Availability of IRCCFunded Resettlement and Settlement Services," http://www. rstp.ca/wp-content/uploads/2016/o7/Responsibilities-ofSponsorship-Groups-Availability-of-IRCC-Resettlemen.... pdf.

58 Liisa H. Malkki, The Need to Help: The Domestic Arts of International Humanitarianism (Durham, NC: Duke University Press, 2015).

59 Enns, Good Gingrich, and Perez, "Religious Heritage."

60 In an interview with Aksu Akçaoğlu, Loïc Wacquant clarifies Pierre Bourdieu's concept of social field and symbolic power. See Loïc Wacquant and Aksu Akçaoğlu, "Practice and Symbolic Power in Bourdieu: The View from Berkeley," Journal of Classical Sociology 17, no. 1 (2017): 45.

61 Epp-Tiessen, Mennonite Central Committee, 150.

62 Sponsor, focus group 4.

63 Sponsor, focus group 2.

64 MCC, "Vision and Mission."

65 Sponsor, focus group 5 a.

66 Sponsor, focus group 2.

67 Sponsor, focus group 3 a.

68 Sponsor, focus group 5 a.

69 Sponsor, focus group $5 b$.

70 Sponsor, focus group 6.

71 MCC, "About MCC," 2019, https://mcccanada.ca/learn/about.

72 Sponsor, focus group 2.

73 MCC, "Where We Work," 2019, https://mcccanada.ca/learn/ where.

74 Epp-Tiessen, Mennonite Central Committee, 235.
75 MCC, "Refugee Response," 2019, https://mcccanada.ca/ learn/what/refugees/sponsorship.

76 Dyck, "Private Refugee Sponsorship in Canada," 14.

77 Treviranus and Casasola, "Canada's Private Sponsorship of Refugees Program," 195.

78 Rachel Bergen, "MCC Resettles One-Third of Canada's BVOR Refugees," MCC, 2018, https://mcccanada.ca/stories/ mcc-resettles-one-third-canadas-bvor-refugees.

79 Dyck, "Private Refugee Sponsorship in Canada."

8o Christopher Kyriakides, Lubna Bajjali, Arthur McLuhan, and Karen Anderson, "Beyond Refuge: Contested Orientalism and Persons of Self-Rescue," Canadian Ethnic Studies 50, no. 2 (2018): 61.

81 Hynie, "Canada's Syrian Refugee Program," 3.

82 Hynie, "Canada's Syrian Refugee Program," 4. See Mike Berry, Inaki Garcia-Blanco, and Kerry Moore, "Press Coverage of the Refugee and Migrant Crisis in the EU: A Content Analysis of Five European Countries," 2016, http:// www.unhcr.org/56bb369c9.html; Vlad Petre Glăveanu, Constance de Saint-Laurent, and Ioana Literat, "Making Sense of Refugees Online: Perspective Taking, Political Imagination, and Internet Memes," American Behavioral Scientist 62, no. 4 (2018): 440-57; Simon Goodman, Ala Sirriyeh, and Simon McMahon, "The Evolving (Re)categorisations of Refugees Throughout the 'Refugee/Migrant Crisis," Journal of Community and Applied Social Psychology 27 (2017): 105-14.

83 Kyriakides et al., "Beyond Refuge," 60.

84 Donna L. Lybecker, Mark K. McBeth, Adam M. Brewer, and Carine De Sy, "The Social Construction of a Border: The us-Canada Border," Journal of Borderlands Studies 33, no. 4 (2018): 529-47.

85 Elke Winter, Anke Patzelt, and Mélanie Beauregard, "L'Imaginaire National, l'Asile et les Réfugiés Syriens en Allemagne et au Canada: Une Analyse Discursive," Canadian Ethnic Studies 50, no. 2 (2018): 15-34.

86 Hynie, "Canada's Syrian Refugee Program," 4.

87 Mcco, "Committee Roles Template."

88 Hynie, "Canada's Syrian Refugee Program," 4.

89 Sponsor, focus group 5a.

90 Sponsor, focus group 4.

91 Sponsor, focus group 5 a.

92 Sponsor, focus group $5 \mathrm{~b}$.

93 For an insightful discussion of pedagogy and the nature of relationships, see Dorothy Vaandering, "Critical Relational Theory," in Restorative Theory in Practice: Insights into What Works and Why, ed. Belinda Hopkins, 63-76 (London: Jessica Kingsley Publishers, 2016).

94 Sponsor, focus group 4.

95 Sponsor, focus group 1.

96 Sponsor, focus group 1.

97 Sponsor, focus group 5a.

98 Sponsor, focus group 6.

99 Sponsor, focus group $5 \mathrm{~b}$. 
100 Sponsor, focus group 3.

101 Sponsor, focus group 1.

102 Wendy Adema, "Month 13: From Sponsorship to Integration," MCC, 2019, https://mcccanada.ca/stories/month-13sponsorship-integration.

103 A divided habitus, inclined toward the conciliation of contraries, functions to preserve a subordinate social field and protect one's assets-particularly one's symbolic power-in that system of capital. A cleft habitus permits the simultaneous occupation of dominant and dominated social positions in conflicting social fields. For example, agents may maintain material and symbolic assets and an upward trajectory in a secondary system of capital while having minimal capacity to accrue capital in the market-state social field. Integrated ambiguity is to see and know different and often contradictory systems of capital and divergent rules of the game all at once, and to be inclined towards practices that preserve a coherent yet ambiguous self. See Good Gingrich, Out of Place.

104 Good Gingrich, Out of Place, 219.

105 Alain Epp Weaver, "MCC's Operating Principles and Essential Elements of Change" (Akron, oH: Mennonite Central
Committee, Planning Learning Disaster Response Department, 2018), 1.

106 Epp Weaver, “McC’s Operating Principles”, 2.

107 Epp Weaver, “McC's Operating Principles,” 2.

108 See, for example, Royden Loewen, "Boxing Up the Old Colony Mennonites," Canadian Mennonite, 14 August 2013. Paulo Freire, in his famous Pedagogy of the Oppressed, identifies that people sometimes accept that they have been made "beings for others," reduced to the level of a category or even object by unjust social relations. He calls for transformed social structures that allow people to become "beings for themselves," to be fully human. Paulo Freire, Pedagogy of the Oppressed, 3oth ed. (New York: Continuum, 2005), 73-5.

Luann Good Gingrich is an associate professor and the director of the Global Labour Research Centre at York University. She can be reached at luanngg@yorku.ca.

Thea Enns works in the area of refugee resettlement in Canada. She can be reached at t.s.enns@gmail.com. 